\title{
ESTIMATIVA DE COEFICIENTES DE CORRELAÇÃO E TRILHA EM GERAÇÕES SEGREGANTES DE TRIGO HEXAPLÓIDE $\left({ }^{1}\right)$
}

\author{
IRINEU HARTWIG $\left({ }^{2 *}, 4\right)$; FERNANDO IRAJÁ FÉLIX DE CARVALHO $\left({ }^{2}\right)$; ANTÔNIO COSTA \\ DE OLIVEIRA $\left({ }^{2}\right)$; EDUARDO ALANO VIEIRA $\left({ }^{3}\right)$, JOSÉ ANTÔNIO GONZALES DA SILVA $\left({ }^{2}\right)$; \\ IVANDRO BERTAN $(2,5)$; GUILHERME RIBEIRO $(2,5)$; TACIANE FINATTO $\left({ }^{2,4}\right)$; \\ CECÍLIA ESTIMA SACRAMENTO DOS REIS $\left({ }^{2,5}\right)$; CYRANO CARDOSO BUSATO $\left({ }^{2,4}\right)$
}

\begin{abstract}
RESUMO
Conhecer como os caracteres agronômicos se correlacionam nas populações segregantes é primordial ao melhorista de plantas, principalmente quando o objetivo for seleção indireta, por meio de um caráter de fácil mensuração ou de maior herdabilidade correlacionado ao caráter de interesse de menor herdabilidade. Dessa forma, a partir da variabilidade observada em caracteres agronômicos nas gerações F2 e F3 de quatro cruzamentos de trigo, avaliados no ano agrícola de 2004, no Centro Agropecuário da Palma, do Centro de Genômica e Fitomelhoramento - FAEM/UFPel, localizado no município de Capão do Leão (RS), este trabalho teve como objetivos estimar: a) coeficientes de correlação genotípica, fenotípica e de ambiente entre os caracteres; b) coeficientes de trilha sobre o rendimento de grãos. Em todas as populações avaliadas, por meio das correlações simples, a seleção de plantas mais produtivas pode ser realizada pela seleção indireta sobre número de afilhos férteis por planta. Mediante a análise de trilha foi possível identificar o efeito indireto do caráter número de afilhos férteis como causador da formação da correlação entre outros caracteres (comprimento da espiga $x$ rendimento de grãos, número de espiguetas da espiga $x$ rendimento de grãos e número de grãos da espiga $x$ rendimento de grãos), enfatizando que o número de afilhos férteis é o principal caráter a ser considerado na obtenção de ganhos em produção por planta.
\end{abstract}

Palavras-chave: Triticum aestivum L., seleção indireta, genética quantitativa, herdabilidade.

\section{ABSTRACT \\ ESTIMATIVE OF CORRELATION AND PATH COEFFICIENTS IN HEXAPLOID WHEAT SEGREGATING POPULATIONS}

The knowledge of how the agronomical traits are correlated in segregating populations is of primary importance for plant breeders, specially when one considers indirect selection through a character easily measurable or with high heritability correlated to the trait of interest with lower heritability. Agronomical traits in F2 and F3 generations of four wheat crosses, were evaluated on 2004 agricultural year in the Centro Agropecuário da Palma, of the Centro de Genômica e Fitomelhoramento - FAEM/

( $\left.{ }^{1}\right)$ Recebido para publicação em 30 de janeiro de 2006 e aceito em 15 de dezembro de 2006.

$\left({ }^{2}\right)$ Centro de Genômica e Fitomelhoramento - Faculdade de Agronomia “Eliseu Maciel” (FAEM)/Universidade Federal de Pelotas (UFPel). Caixa Postal 354, 96010-900 Pelotas (RS). E-mail: iriwig@gmail.com (*) Autor correspondente; carvalho@ufpel.tche.br; acostol@terra.com.br; jagsfaem@yahoo.com.br; ivandrobertan@yahoo.com.br; guilhermers@yahoo.com.br; tacifinatto@yahoo.com.br; ceciliasacramento@gmail.com; cyrano_agronomo@yahoo.com.br.

$\left({ }^{3}\right)$ Embrapa Cerrados, Caixa Postal 08223, 73310-970 Planaltina (DF). E-mail: vieiraea@cpac.embrapa.br

$\left({ }^{4}\right)$ Bolsista CNPq.

$\left({ }^{5}\right)$ Bolsista Capes. 
UFPel, located in Capão do Leão country in Rio Grande do Sul State. The present work had the objectives to estimate for evaluated traits: a) genotypic, phenotypic and environmental correlation coefficients between the traits; and b) path coefficients for grain yield. For all populations, the single correlations indicated that the selection of higher yielding plants can be performed by indirect selection for number of fertile tillers per plant. The path analysis showed that it was possible to identify the indirect effect of the trait number of fertile tillers the as cause of the correlation between other traits (ear length $x$ grain yield, spikelet number per ear $x$ grain yield and number of ear grain $x$ grain yield). Thus suggesting that the number of fertile tillers is the major trait to select for in order to obtain gains on grain yield.

Key-words: Triticum aestivum L., indirect selection, quantitative genetics, heritability.

\section{INTRODUÇÃO}

Estudos sobre as correlações entre caracteres mensuráveis em uma população permitem inferências sobre sua interdependência, isto é, se tendem ou não a permanecer associados nas progênies durante os sucessivos ciclos de seleção (JoHNSON et al., 1966; Fonseca e Patterson, 1968). Esse conhecimento é primordial quando o objetivo é a seleção simultânea (mais de um caráter), ou quando o caráter de interesse expressa baixa herdabilidade ou é de difícil mensuração (SANTOS e VENCOVSKY, 1986).

No melhoramento genético, quando a seleção é realizada com base em plantas individuais, em gerações com elevada freqüência de heterozigotos, fatores relacionados à ação gênica, ao efeito de ambiente e à reduzida disponibilidade de sementes são os mais restritivos (BENIN et al., 2005). Tais fatores, somados à heterogeneidade do solo e à dificuldade de selecionar em ambientes distintos, acabam determinando maior erro experimental. Nessas condições, procedimentos estatísticos que possibilitem a partição da variância fenotípica em componentes genotípicos, principalmente, em gerações com elevada freqüência de heterozigotos, são altamente desejáveis. Em vista desses efeitos, a correlação fenotípica pode ter pouca aplicabilidade, podendo induzir o melhorista a estratégias pouco efetivas ( Chaudaury, 1973). Assim, é importante distinguir as causas genéticas e de ambiente que, combinadas, resultam na correlação fenotípica (Almeida, 1988).

Benin et al. (2005) relaciona a semelhança dos conceitos de correlação com os de herdabilidade, e assegura que as interpretações da correlação devem ser restritas à constituição genética avaliada assim como ao ambiente sob estudo. Todavia, se assegurada a elevada magnitude tanto da correlação fenotípica, quanto da genotípica nas diferentes populações segregantes de um conjunto de cruzamentos, pode-se tentar inferir sobre uma estratégia generalizada de seleção, via seleção indireta naquele caráter a qual seja de mais fácil execução e/ou tenha a maior herdabilidade.
Existem diversos métodos para a obtenção de estimativas de correlação em plantas autógamas, desenvolvidos em função do delineamento experimental, das características próprias de diferentes populações e do ambiente de cultivo (CARvalho et al., 2004). Dentre esses, aqueles utilizados em gerações segregantes destacam-se por separar o componente genético e o de ambiente por meio da avaliação dos genitores e de suas respectivas populações (Petr e Frey, 1966; Kurek et al., 2002). Neste contexto, é importante investigar que proporções podem ser atribuídas a fatores genéticos, a fim de se verificar a possibilidade de resposta à seleção nas gerações seguintes de melhoramento. A alta correlação entre dois caracteres porém, pode ser resultado do efeito de um terceiro caráter sobre eles, ou um grupo de caracteres (CRUz e RegazzI, 1994). Com o intuito de entender melhor a associação entre caracteres, WRIGHT (1921) propôs o método denominado análise de trilha (path analysis) que desdobra as correlações estimadas em efeitos diretos e indiretos de cada caráter sobre uma variável básica. Baseia-se na avaliação do efeito de uma variável independente $(\mathrm{x})$ sobre uma variável dependente (y), após a remoção da influência de todas as outras variáveis independentes $\left(\mathrm{x}_{\mathrm{i}}\right)$ incluídas na análise.

O objetivo do presente trabalho foi estimar os coeficientes de correlação genotípica, fenotípica e de ambiente, entre os caracteres estatura de planta, número de afilhos férteis por planta, comprimento da espiga principal, número de espiguetas da espiga principal, massa da espiga principal, número de grãos da espiga principal, massa de grãos da espiga principal, massa de mil grãos e rendimento de grãos e os coeficientes de trilha sobre o rendimento de grãos, por meio da análise das gerações $F_{2}$ e $F_{3}$ em quatro cruzamentos de trigo.

\section{MATERIAL E MÉTODOS}

No segundo semestre do ano de 2002, foram realizados quatro cruzamentos artificiais em telado: CEP 24 x PF 87504, FUNDACEP 29 x BR 18, BRS $49 x$ 
BR 23 e BR 23 x PF 950354. As sementes híbridas $\left(\mathrm{F}_{1}\right)$ de cada cruzamento foram colhidas e semeadas em baldes contendo solo, em fevereiro de 2003, em telado, objetivando o avanço de geração, ou seja, a obtenção de sementes $\mathrm{F}_{2}$. Um bulk (amostra) de sementes $\mathrm{F}_{2}$ de cada cruzamento (sem seleção) foi semeado em baldes, no segundo semestre de 2003 em telado, para o avanço da geração $F_{2}$ para $F_{3}$.

O experimento em campo foi instalado no ano agrícola de 2004, no Centro Agropecuário da Palma, na área experimental do Centro de Genômica e Fitomelhoramento - FAEM/UFPel, localizado no município de Capão do Leão (RS). O município está situado a $31^{\circ} 52^{\prime} 00^{\prime \prime}$ de latitude Sul e $52^{\circ} 21^{\prime} 24^{\prime \prime}$ de longitude Oeste, a uma altitude de 13, $24 \mathrm{~m}$, sendo o clima do tipo Cfa, com uma precipitação pluviométrica média anual de 1280,2 mm (MORENo, 1961). O solo da área experimental pertence à unidade de mapeamento Pelotas, classificado como Argissolo com relevo ondulado (EMBRAPA, 1999).

A área experimental foi preparada de forma convencional e adubada de acordo com a análise de solo. Para o controle das plantas invasoras, foi efetuada a aplicação do produto designado comercialmente Basagran, de acordo com as indicações técnicas para a cultura do trigo (RCSBPT, 2003) e capina manual, quando necessário.

O delineamento empregado no experimento foi o completamente casualizado, em que cada planta foi considerada uma unidade experimental, sendo desconsideradas as plantas das bordaduras. As populações foram cultivadas em linhas de $3 \mathrm{~m}$ de comprimento, espaçado de $0,3 \mathrm{~m}$ entre e dentro da linha. As linhas dos genitores do cruzamento e suas respectivas populações segregantes $F_{2}$ e $F$ foram distribuídas de forma aleatória dentro de cada parcela.

Foram avaliados os seguintes caracteres: 1) estatura de planta (EP), aferida em centímetros, da base (nível do solo) até ápice da espiga do colmo principal, excluindo as aristas; 2 ) número de afilhos férteis por planta (NAF), computando o número de afilhos com espigas férteis por planta; 3) massa da espiga principal (MEP), marcada a campo com uma fita adesiva no momento do florescimento, em gramas após a colheita; 4) comprimento da espiga principal (CEP), aferida em centímetros, da base da espiga (inserção das primeiras espiguetas) até o ápice, excluindo as aristas; 5) número de espiguetas da espiga principal (NEEP), contagem do número de espiguetas da espiga principal; 6) número de grãos da espiga principal (NGEP), contagem do número total de grãos da espiga principal; 7) massa de grãos da espiga principal (MGEP), aferida em gramas após a trilha da espiga principal; 8) massa de mil grãos
(MMG), em gramas, determinada pela estimativa da massa média de um grão da espiga principal e posterior multiplicação por mil; e 9) rendimento de grãos por planta, em gramas, determinado pela trilha de todas as espigas férteis da planta.

A fórmula para o cálculo da correlação fenotípica $\left(r_{p}\right)$ seguiu o modelo descrito por STEEL e TORRIE (1960):

$$
r_{P}=\frac{C O V_{F 2 X Y}}{\sqrt{\left(V_{X} x V_{Y}\right)}}
$$

sendo: COVF2XY - Covariância entre os caracteres $\mathrm{X}$ e $\mathrm{Y}$; $\mathrm{V}_{\mathrm{x}}$ e $\mathrm{V}_{\mathrm{y}}$ - Variância dos caracteres $\mathrm{X}$ e Y.

A correlação genotípica (rg) foi estimada por meio do modelo de Petr e Frey (1966), adaptado por BENIN et al. (2005):

$$
r_{G}=\frac{C O V_{F 2 X Y}-\left(\frac{C_{P} V_{P 1 X Y}+C O V_{P 2 X Y}}{2}\right)}{\sqrt{\left(V_{F 2 X}-\left(\frac{V_{P 1 X}+V_{P 2 X}}{2}\right)\right) \times\left(V_{F 2 Y}-\left(\frac{V_{P 1 Y}+V_{P 2 Y}}{2}\right)\right)}}
$$

sendo: COVP1XY, COVP2XY - Covariâncias dos genitores P1 e P2 para os caracteres X e Y; COVF2XY - Covariância da população $F_{2}$ para os caracteres X e Y; VF2X e VF2Y - Variância da população $F_{2}$ para os caracteres $X$ e $Y$; VP1X, VP1Y e VP2X, VP2Y - Variância dos genitores P1 e P2 para os caracteres $\mathrm{X}$ e $\mathrm{Y}$. A correlação de ambiente $\left(\mathrm{r}_{\mathrm{E}}\right)$ foi obtida pela equação:

$$
r_{E}=\frac{\left(\frac{C O V_{P 1 X Y}+C O V_{P 2 X Y}}{2}\right)}{\sqrt{\left(\left(\frac{V_{P 1 X}+V_{P 2 X}}{2}\right) \times\left(\frac{V_{P 1 Y}+V_{P 2 Y}}{2}\right)\right)}}
$$

Para as estimativas das correlações na geração $\mathrm{F}_{3}$, apenas substituiu-se a variância e covariância de $\mathrm{F}_{2}$ pelas de $\mathrm{F}$ do mesmo modelo.

A estatística do teste $t$ foi utilizada para a verificação formal de hipóteses, para determinar se existe correlação linear significativa entre duas variáveis. Esse método utiliza a distribuição $t$ de Student (CARvalHo et al., 2004), com n - 2 graus de liberdade, através do seguinte modelo: ${ }_{\mathrm{t}} \frac{\mathrm{r}}{\sqrt{1 \mathrm{r}^{2}}} \sqrt{\mathrm{n}^{2}}$, sendo: $r$ - coeficiente de correlação entre os caracteres $\mathrm{X}$ e $\mathrm{Y} ; \mathrm{r}^{2}$ - grau de ajuste da reta de regressão aos dados, ou simplesmente $(\mathrm{r})^{2} ; \mathrm{n}$ - graus de liberdade correspondentes a cada geração (P1, P2 e $F_{2}$ ou $F_{3}$ ). 
A análise de trilha foi realizada a partir da matriz de correlações genotípicas, após diagnóstico da colinearidade e exclusão de variáveis explicativas problemas quando necessária, com o auxílio do programa computacional GENES (CRUZ, 2001), considerando o caráter rendimento de grãos como a variável dependente, e estatura de planta, número de afilhos férteis por planta, massa da espiga principal, comprimento da espiga principal, número de espiguetas da espiga principal, número de grãos da espiga principal, massa de grãos da espiga principal, massa de mil grãos como variáveis explicativas.

\section{RESULTADOS E DISCUSSÃO}

Nas tabelas 1, 2, 3 e 4, observam-se as correlações fenotípicas $\left(r_{p}\right)$, genotípicas $\left(r_{g}\right)$ e de ambiente $\left(r_{\mathrm{E}}\right)$ entre os caracteres estatura de plantas (EP), número de afilhos férteis por planta (NAF), comprimento da espiga principal (CEP), número de espiguetas da espiga principal (NEEP), massa da espiga principal (MEP), número de grãos da espiga principal (NGEP), massa de grãos da espiga principal (MGEP), massa de mil grãos (MMG) e rendimento de grãos da planta (RG) nas gerações F2 e F3 dos quatro cruzamentos de trigo utilizados neste trabalho.

Tabela 1. Coeficientes de correlações fenotípicas $\left(r_{p}\right)$, genotípicas $\left(r_{g}\right)$ e de ambiente $\left(r_{E}\right)$ entre os caracteres estatura de plantas (EP), número de afilhos férteis por planta (NAF), comprimento da espiga principal (CEP), número de espiguetas da espiga principal (NEEP), massa da espiga principal (MEP), número de grãos da espiga principal (NGEP), massa de grãos da espiga principal (MGEP), massa de mil grãos (MMG) e rendimento de grãos da planta (RG) das gerações $\mathrm{F}_{2}$ (acima da diagonal) e $\mathrm{F}_{3}$ (abaixo da diagonal) do cruzamento CEP 24 x PF 87504. FAEM/UFPel. Pelotas/RS, 2005

\begin{tabular}{|c|c|c|c|c|c|c|c|c|c|c|}
\hline Caráter & & $\mathrm{EP}$ & NAF & CEP & NEEP & MEP & NGEP & MGEP & MMG & RG \\
\hline \multirow[t]{3}{*}{$\mathrm{EP}$} & $r_{p}$ & - & $0,41^{*}$ & $0,18^{*}$ & $0,22 *$ & $0,20^{*}$ & 0,05 & $0,22^{*}$ & $0,30^{*}$ & $0,53^{*}$ \\
\hline & $r_{g}$ & - & 0,50 * & $0,26^{*}$ & $0,37^{*}$ & $0,21^{*}$ & 0,02 & $0,26^{*}$ & $0,47^{*}$ & $0,62 *$ \\
\hline & $\mathrm{r}_{\mathrm{e}}$ & - & $0,22^{*}$ & 0,03 & $-0,03$ & $0,19 *$ & $0,20^{*}$ & 0,12 & 0,01 & $0,33^{*}$ \\
\hline \multirow[t]{3}{*}{ NAF } & $r_{p}$ & 0,15 & - & 0,15 & $0,20 *$ & $0,25^{*}$ & 0,13 & $0,26^{*}$ & 0,18 & $0,85^{*}$ \\
\hline & $r_{g}$ & 0,11 & - & 0,19 * & $0,23^{*}$ & $0,27^{*}$ & 0,11 & $0,27^{*}$ & 0,20 * & $0,98^{*}$ \\
\hline & $\mathrm{r}_{\mathrm{e}}$ & $0,22^{*}$ & - & 0,09 & 0,15 & 0,20 * & $0,28^{*}$ & $0,25^{*}$ & 0,16 & $0,60^{*}$ \\
\hline \multirow[t]{3}{*}{ CEP } & $r_{p}$ & 0,00 & 0,07 & - & $0,25^{*}$ & $0,44^{*}$ & $0,30^{*}$ & $0,38^{*}$ & 0,15 & $0,26^{*}$ \\
\hline & $r_{g}$ & $-0,01$ & 0,06 & - & 0,02 & $0,47^{*}$ & $0,27^{*}$ & $0,47^{*}$ & $0,33^{*}$ & $0,38^{*}$ \\
\hline & $\mathrm{r}_{\mathrm{e}}$ & 0,03 & 0,09 & - & $0,57^{*}$ & $0,40^{*}$ & $0,54^{*}$ & 0,17 & $-0,08$ & 0,05 \\
\hline \multirow[t]{3}{*}{ NEEP } & $r_{p}$ & 0,02 & 0,08 & $0,53^{*}$ & - & $0,41^{*}$ & $0,45^{*}$ & $0,36^{*}$ & $-0,06$ & 0,19 * \\
\hline & $r_{g}$ & 0,08 & $-0,03$ & $0,50^{*}$ & - & $0,58^{*}$ & $0,51^{*}$ & $0,60^{*}$ & 0,16 & 0,15 \\
\hline & $\mathrm{r}_{\mathrm{e}}$ & $-0,03$ & 0,15 & $0,57^{*}$ & - & 0,14 & $0,47^{*}$ & $-0,09$ & $-0,31^{*}$ & $0,25^{*}$ \\
\hline \multirow[t]{3}{*}{ MEP } & $r_{p}$ & $-0,03$ & 0,01 & $0,59 *$ & $0,53^{*}$ & - & $0,79 *$ & $0,90 *$ & $0,26^{*}$ & $0,41^{*}$ \\
\hline & $r_{g}$ & $-0,11$ & $-0,09$ & $0,69^{*}$ & $0,91^{*}$ & - & $0,87^{*}$ & $0,95^{*}$ & 0,13 & $0,47^{*}$ \\
\hline & $\mathrm{r}_{\mathrm{e}}$ & $0,19^{*}$ & 0,20 & $0,40^{*}$ & 0,14 & - & $0,46^{*}$ & $0,74^{*}$ & $0,51^{*}$ & $0,25^{*}$ \\
\hline \multirow[t]{3}{*}{ NGEP } & $r_{p}$ & $-0,10$ & 0,01 & $0,44^{*}$ & $0,49 *$ & $0,74^{*}$ & - & $0,76^{*}$ & $-0,18$ & $0,25^{*}$ \\
\hline & $r_{g}$ & $-0,17$ & $-0,08$ & $0,46^{*}$ & $0,68^{*}$ & $0,79 *$ & - & $0,85^{*}$ & $-0,21^{*}$ & $0,26^{*}$ \\
\hline & $\mathrm{r}_{\mathrm{e}}$ & $0,20^{*}$ & $0,28^{*}$ & $0,54^{*}$ & $0,47^{*}$ & $0,46^{*}$ & - & $0,28^{*}$ & $-0,17$ & $0,28^{*}$ \\
\hline \multirow[t]{3}{*}{ MGEP } & $r_{p}$ & $-0,03$ & $-0,02$ & $0,52^{*}$ & $0,51^{*}$ & $0,93^{*}$ & $0,76^{*}$ & - & $0,46^{*}$ & $0,42^{*}$ \\
\hline & $r_{g}$ & $-0,08$ & $-0,15$ & 0,69 * & $0,97^{*}$ & $0,97^{*}$ & $0,84^{*}$ & - & $0,29 *$ & $0,48^{*}$ \\
\hline & $\mathrm{r}_{\mathrm{e}}$ & 0,12 & $0,25^{*}$ & $0,17^{*}$ & $-0,09$ & $0,74^{*}$ & $0,28^{*}$ & - & $0,84^{*}$ & $0,28^{*}$ \\
\hline \multirow[t]{3}{*}{ MMG } & $r_{p}$ & 0,10 & $-0,03$ & 0,19 * & 0,10 & $0,45^{*}$ & $-0,16^{*}$ & $0,52^{*}$ & - & $0,24^{*}$ \\
\hline & $r_{g}$ & 0,14 & $-0,17^{*}$ & $0,36^{*}$ & $0,52^{*}$ & $0,44^{*}$ & $-0,17^{*}$ & $0,42^{*}$ & - & $0,31^{*}$ \\
\hline & $r_{e}$ & 0,01 & $0,16^{*}$ & $-0,08$ & $-0,31^{*}$ & $0,51^{*}$ & $-0,17^{*}$ & $0,84^{*}$ & - & 0,14 \\
\hline \multirow[t]{3}{*}{ RG } & $r_{p}$ & $0,22^{*}$ & $0,81^{*}$ & $0,20^{*}$ & $0,17^{*}$ & $0,23^{*}$ & 0,13 & $0,20^{*}$ & 0,12 & - \\
\hline & $r_{g}$ & 0,14 & $0,97^{*}$ & $0,35^{*}$ & 0,05 & $0,25^{*}$ & 0,10 & $0,19 *$ & 0,12 & - \\
\hline & $\mathrm{r}_{\mathrm{e}}$ & $0,33^{*}$ & 0,60 * & 0,05 & $0,25^{*}$ & $0,25^{*}$ & $0,28^{*}$ & $0,28^{*}$ & 0,14 & - \\
\hline
\end{tabular}

* significativo a $1 \%$ de probabilidade de erro pelo teste $t$. Para dados de $F_{2}(G L=199)$ e $F_{3}(G L=294)$. 
Os coeficientes de correlações fenotípicas $\left(\mathrm{r}_{\mathrm{p}}\right)$, genotípicas $\left(\mathrm{r}_{\mathrm{g}}\right)$ e de ambiente $\left(\mathrm{r}_{\mathrm{E}}\right)$ obtidos neste trabalho revelaram que existem diferenças tanto na magnitude, como no sentido das correlações entre os caracteres estudados nas duas gerações dos quatro cruzamentos. Essa discordância pode ser atribuída a efeitos modificadores do ambiente e a diferentes mecanismos fisiológicos controlando a expressão desses caracteres (FALCONER 1987; CARVALHO et al., 2004), bem como às diferenças na capacidade de combinação dos genitores (LORENCETTI, 2004). Esse fato implica que não podemos inferir somente sobre a correlação entre os caracteres de forma generalizada (desconsiderando cruzamentos e/ ou gerações).

Em ambas as gerações dos quatro cruzamentos, os coeficientes de correlações genotípicas $\left(\mathrm{r}_{\mathrm{g}}\right)$ mostraram ser, em sua maioria, superiores aos coeficientes de correlações fenotípicas $\left(r_{p}\right)$. Resultados similares foram relatados por CAMARGO et al. (2000), SiLva et al. (2005) em trigo, por Benin et al. (2005) em aveia, e Moro et al. (1992), TAWARE et al. (1997) e LOPES et al. (2002) em soja. De acordo com GonçALVES et al. (1996), essa superioridade pode ser justificada pelo resultado dos efeitos modificadores do ambiente na associação entre os caracteres.

Tabela 2. Coeficientes de correlações fenotípicas $\left(r_{p}\right)$, genotípicas $\left(r_{g}\right)$ e de ambiente $\left(r_{e}\right)$ entre os caracteres estatura de plantas (EP), número de afilhos férteis por planta (NAF), comprimento da espiga principal (CEP), número de espiguetas da espiga principal (NEEP), massa da espiga principal (MEP), número de grãos da espiga principal (NGEP), massa de grãos da espiga principal (MGEP), massa de mil grãos (MMG) e rendimento de grãos da planta (RG) das gerações $\mathrm{F}_{2}$ (acima da diagonal) e $\mathrm{F}_{3}$ (abaixo da diagonal) do cruzamento FUNDACEP 29 x BR 18. FAEM/ UFPel. Pelotas/RS. 2005

\begin{tabular}{|c|c|c|c|c|c|c|c|c|c|c|}
\hline Caráter & & $\mathrm{EP}$ & NAF & CEP & NEEP & MEP & NGEP & MGEP & MMG & RG \\
\hline \multirow[t]{3}{*}{$\mathrm{EP}$} & $r_{p}$ & - & $0,31^{*}$ & 0,14 & 0,19 & $0,21^{*}$ & 0,18 & $0,23^{*}$ & 0,17 & $0,35^{*}$ \\
\hline & $r_{g}$ & - & $0,56^{*}$ & 0,18 & $0,37^{*}$ & $0,34^{*}$ & $0,28^{*}$ & $0,31^{*}$ & 0,18 & $0,57^{*}$ \\
\hline & $\mathrm{r}_{\mathrm{e}}$ & - & 0,07 & 0,07 & $-0,07$ & $-0,03$ & $-0,03$ & 0,04 & 0,15 & 0,09 \\
\hline \multirow[t]{3}{*}{ NAF } & $r_{p}$ & 0,09 & - & $0,25^{*}$ & $0,33^{*}$ & $0,25^{*}$ & $0,26^{*}$ & $0,24^{*}$ & 0,05 & $0,81^{*}$ \\
\hline & $r_{g}$ & 0,11 & - & $0,56^{*}$ & $0,84^{*}$ & $0,51^{*}$ & $0,48^{*}$ & $0,46^{*}$ & 0,17 & $0,91^{*}$ \\
\hline & $\mathrm{r}_{\mathrm{e}}$ & 0,07 & - & $-0,01$ & 0,00 & 0,05 & 0,07 & 0,04 & $-0,03$ & $0,75^{*}$ \\
\hline \multirow[t]{3}{*}{ CEP } & $r_{p}$ & 0,20 * & 0,02 & - & 0,59 * & $0,41^{*}$ & $0,37^{*}$ & 0,30 * & 0,03 & $0,24^{*}$ \\
\hline & $r_{g}$ & $0,25^{*}$ & 0,04 & - & $0,70^{*}$ & $0,47^{*}$ & $0,36^{*}$ & $0,31^{*}$ & 0,17 & $0,44^{*}$ \\
\hline & $\mathrm{r}_{\mathrm{e}}$ & 0,07 & $-0,01$ & - & $0,48^{*}$ & $0,33^{*}$ & $0,37^{*}$ & $0,28^{*}$ & $-0,15$ & 0,05 \\
\hline \multirow[t]{3}{*}{ NEEP } & $r_{p}$ & $0,16^{*}$ & $0,26^{*}$ & $0,39 *$ & - & $0,56^{*}$ & $0,58^{*}$ & $0,47^{*}$ & 0,09 & $0,42^{*}$ \\
\hline & $r_{g}$ & $0,26^{*}$ & $0,51^{*}$ & $0,34^{*}$ & - & $0,63^{*}$ & $0,68^{*}$ & $0,51^{*}$ & 0,18 & $0,92^{*}$ \\
\hline & $\mathrm{r}_{\mathrm{e}}$ & $-0,07$ & 0,00 & $0,48^{*}$ & - & $0,50^{*}$ & $0,48^{*}$ & $0,44^{*}$ & 0,01 & 0,04 \\
\hline \multirow[t]{3}{*}{ MEP } & $r_{p}$ & $0,28 *$ & $0,29 *$ & $0,47^{*}$ & $0,58^{*}$ & - & $0,86^{*}$ & $0,93^{*}$ & $0,56^{*}$ & $0,48^{*}$ \\
\hline & $r_{g}$ & $0,51^{*}$ & $0,60^{*}$ & $0,61^{*}$ & $0,68^{*}$ & - & $0,92^{*}$ & $0,94^{*}$ & $0,76^{*}$ & $0,83^{*}$ \\
\hline & $\mathrm{r}_{\mathrm{e}}$ & $-0,03$ & 0,05 & $0,33^{*}$ & $0,50 *$ & - & $0,78^{*}$ & $0,93 *$ & $0,32^{*}$ & 0,18 \\
\hline \multirow[t]{3}{*}{ NGEP } & $r_{p}$ & $0,25^{*}$ & $0,25^{*}$ & $0,44^{*}$ & $0,61^{*}$ & $0,86^{*}$ & - & $0,87^{*}$ & $0,28^{*}$ & $0,41^{*}$ \\
\hline & $r_{g}$ & $0,43^{*}$ & $0,48^{*}$ & $0,50^{*}$ & $0,73^{*}$ & $0,95^{*}$ & - & $0,90^{*}$ & $0,62^{*}$ & $0,60^{*}$ \\
\hline & $\mathrm{r}_{\mathrm{e}}$ & $-0,03$ & 0,07 & $0,37^{*}$ & $0,48^{*}$ & $0,78^{*}$ & - & $0,81^{*}$ & $-0,13$ & $0,23^{*}$ \\
\hline \multirow[t]{3}{*}{ MGEP } & $r_{p}$ & $0,25^{*}$ & $0,30^{*}$ & $0,40^{*}$ & $0,50^{*}$ & $0,99^{*}$ & $0,85^{*}$ & - & $0,69 *$ & $0,44^{*}$ \\
\hline & $r_{g}$ & $0,40^{*}$ & $0,63^{*}$ & $0,50^{*}$ & $0,56^{*}$ & $0,98^{*}$ & $0,89^{*}$ & - & $0,86^{*}$ & $0,68^{*}$ \\
\hline & $\mathrm{r}_{\mathrm{e}}$ & 0,04 & 0,04 & $0,28^{*}$ & $0,44^{*}$ & $0,93^{*}$ & $0,81^{*}$ & - & $0,45^{*}$ & $0,21^{*}$ \\
\hline \multirow[t]{3}{*}{ MMG } & $r_{p}$ & 0,13 & $0,18^{*}$ & 0,12 & 0,07 & $0,57^{*}$ & 0,07 & $0,68^{*}$ & - & $0,21^{*}$ \\
\hline & $r_{g}$ & 0,14 & $0,49^{*}$ & $0,33^{*}$ & 0,13 & $0,91^{*}$ & $0,33^{*}$ & $0,98^{*}$ & - & $0,46^{*}$ \\
\hline & $\mathrm{r}_{\mathrm{e}}$ & $0,15^{*}$ & $-0,03$ & $-0,15^{*}$ & 0,01 & $0,32 *$ & $-0,13$ & $0,45^{*}$ & - & 0,00 \\
\hline \multirow[t]{3}{*}{ RG } & $r_{p}$ & 0,29 * & $0,84^{*}$ & $0,17^{*}$ & 0,30 * & $0,51^{*}$ & 0,39 * & $0,48^{*}$ & $0,29 *$ & - \\
\hline & $r_{g}$ & $0,59^{*}$ & $0,96^{*}$ & $0,36^{*}$ & $0,74^{*}$ & $0,92^{*}$ & $0,73^{*}$ & $0,94^{*}$ & $0,95^{*}$ & - \\
\hline & $\mathrm{r}_{\mathrm{e}}$ & 0,09 & $0,75^{*}$ & $0,05^{*}$ & 0,04 & $0,18^{*}$ & $0,23^{*}$ & $0,21^{*}$ & 0,00 & - \\
\hline
\end{tabular}

* significativo a $1 \%$ de probabilidade de erro pelo teste $t$. Para dados de $F_{2}(G L=154)$ e $F_{3}(G L=340)$. 
Tabela 3. Coeficientes de correlações fenotípicas $\left(r_{p}\right)$, genotípicas $\left(r_{g}\right)$ e de ambiente $\left(r_{e}\right)$ entre os caracteres estatura de plantas (EP), número de afilhos férteis por planta (NAF), comprimento da espiga principal (CEP), número de espiguetas da espiga principal (NEEP), peso da espiga principal (PEP), número de grãos da espiga principal (NGEP), peso de grãos da espiga principal (PGEP), peso de mil grãos (PMG) e rendimento de grãos da planta (RG) das gerações $F_{2}$ (acima da diagonal) e $\mathrm{F}_{3}$ (abaixo da diagonal) do cruzamento BRS 49 x BR 23. FAEM/UFPel. Pelotas/RS, 2005

\begin{tabular}{|c|c|c|c|c|c|c|c|c|c|c|}
\hline Caráter & & $\mathrm{EP}$ & NAF & CEP & NEEP & PEP & NGEP & PGEP & PMG & RG \\
\hline \multirow[t]{3}{*}{ EP } & $r_{p}$ & - & 0,11 & 0,14 & 0,03 & $0,50^{*}$ & $0,33^{*}$ & $0,53^{*}$ & $0,52^{*}$ & $0,36^{*}$ \\
\hline & $r_{g}$ & - & 0,08 & 0,20 * & 0,06 & $0,74^{*}$ & $0,47^{*}$ & $0,71^{*}$ & 0,69 * & 0,50 * \\
\hline & $\mathrm{r}_{\mathrm{e}}$ & - & 0,22 & $-0,03$ & $-0,03$ & 0,05 & 0,03 & 0,05 & 0,08 & 0,13 \\
\hline \multirow[t]{3}{*}{ NAF } & $r_{p}$ & $0,19^{*}$ & - & $0,23^{*}$ & $0,39 *$ & $0,15^{*}$ & $0,24^{*}$ & $0,18^{*}$ & 0,04 & $0,73^{*}$ \\
\hline & $r_{g}$ & $0,21^{*}$ & - & $0,54^{*}$ & $0,86^{*}$ & $0,42^{*}$ & $0,56^{*}$ & $0,39 *$ & 0,10 & $0,90^{*}$ \\
\hline & $\mathrm{r}_{\mathrm{e}}$ & $0,22^{*}$ & - & $-0,12$ & $-0,03$ & $-0,09$ & $-0,07$ & $-0,05$ & $-0,02$ & $0,42^{*}$ \\
\hline \multirow[t]{3}{*}{$\overline{\mathrm{CEP}}$} & $r_{p}$ & 0,13 & $0,19^{*}$ & - & $0,46^{*}$ & $0,37^{*}$ & $0,32^{*}$ & $0,32^{*}$ & $0,16^{*}$ & $0,19^{*}$ \\
\hline & $r_{g}$ & $0,18^{*}$ & $0,43^{*}$ & - & $0,29 *$ & $0,19^{*}$ & 0,10 & $0,22^{*}$ & $0,23^{*}$ & $0,19 *$ \\
\hline & $\mathrm{r}_{\mathrm{e}}$ & $-0,03$ & $-0,12$ & - & $0,70^{*}$ & $0,60^{*}$ & $0,64^{*}$ & $0,49^{*}$ & 0,04 & $0,20^{*}$ \\
\hline \multirow[t]{3}{*}{ NEEP } & $r_{p}$ & 0,01 & $0,29 *$ & $0,46^{*}$ & - & $0,45^{*}$ & $0,56^{*}$ & $0,35^{*}$ & $-0,08$ & $0,16^{*}$ \\
\hline & $r_{g}$ & 0,03 & $0,63^{*}$ & $0,31^{*}$ & - & $0,34^{*}$ & $0,56^{*}$ & $0,26^{*}$ & $-0,20^{*}$ & $0,23^{*}$ \\
\hline & $\mathrm{r}_{\mathrm{e}}$ & $-0,03$ & $-0,03$ & $0,70^{*}$ & - & $0,56^{*}$ & $0,56^{*}$ & $0,47^{*}$ & 0,09 & 0,09 \\
\hline \multirow[t]{3}{*}{ PEP } & $r_{p}$ & $0,39 *$ & $0,18^{*}$ & $0,32^{*}$ & $0,32^{*}$ & - & $0,87^{*}$ & $0,99 *$ & $0,63^{*}$ & $0,34^{*}$ \\
\hline & $r_{g}$ & $0,64^{*}$ & $0,55^{*}$ & 0,10 & 0,04 & - & $0,90^{*}$ & $0,95^{*}$ & $0,74^{*}$ & $0,41^{*}$ \\
\hline & $\mathrm{r}_{\mathrm{e}}$ & 0,05 & $-0,09$ & $0,60^{*}$ & $0,56^{*}$ & - & $0,83^{*}$ & $0,92 *$ & $0,49 *$ & $0,27^{*}$ \\
\hline \multirow[t]{3}{*}{ NGEP } & $r_{p}$ & $0,17^{*}$ & $0,22^{*}$ & $0,25^{*}$ & $0,46^{*}$ & $0,93^{*}$ & - & $0,88^{*}$ & $0,21^{*}$ & $0,34^{*}$ \\
\hline & $r_{g}$ & $0,25^{*}$ & $0,56^{*}$ & $-0,02$ & $0,35^{*}$ & $0,98^{*}$ & - & $0,92^{*}$ & $0,29 *$ & $0,43^{*}$ \\
\hline & $\mathrm{r}_{\mathrm{e}}$ & 0,03 & $-0,07$ & $0,64^{*}$ & $0,56^{*}$ & $0,83^{*}$ & - & $0,83^{*}$ & 0,09 & $0,24^{*}$ \\
\hline \multirow[t]{3}{*}{ PGEP } & $r_{p}$ & $0,37^{*}$ & $0,17^{*}$ & $0,24^{*}$ & $0,26^{*}$ & $0,92^{*}$ & $0,94^{*}$ & - & $0,73^{*}$ & $0,39 *$ \\
\hline & $r_{g}$ & $0,51^{*}$ & $0,39 *$ & 0,08 & 0,06 & $0,97^{*}$ & $0,96^{*}$ & - & $0,82^{*}$ & $0,50 *$ \\
\hline & $\mathrm{r}_{\mathrm{e}}$ & 0,05 & $-0,05$ & $0,49^{*}$ & $0,47^{*}$ & $0,92^{*}$ & $0,83^{*}$ & - & $0,59 *$ & $0,27^{*}$ \\
\hline \multirow[t]{3}{*}{ PMG } & $r_{p}$ & $0,40^{*}$ & 0,02 & 0,09 & $-0,13$ & $0,65^{*}$ & $0,19 *$ & $0,75^{*}$ & - & $0,29^{*}$ \\
\hline & $r_{g}$ & $0,52^{*}$ & 0,06 & 0,11 & $-0,30^{*}$ & $0,84^{*}$ & $0,28^{*}$ & $0,88^{*}$ & - & $0,40^{*}$ \\
\hline & $\mathrm{r}_{\mathrm{e}}$ & 0,08 & $-0,02$ & 0,04 & 0,09 & $0,49^{*}$ & 0,09 & $0,59^{*}$ & - & $0,15^{*}$ \\
\hline \multirow[t]{3}{*}{ RG } & $r_{p}$ & $0,41^{*}$ & $0,85^{*}$ & $0,18^{*}$ & $0,20^{*}$ & $0,36^{*}$ & $0,33^{*}$ & $0,36^{*}$ & $0,21^{*}$ & - \\
\hline & $r_{g}$ & $0,78^{*}$ & $0,87^{*}$ & $0,19^{*}$ & $0,39 *$ & $0,57^{*}$ & $0,51^{*}$ & $0,54^{*}$ & $0,31^{*}$ & - \\
\hline & $\mathrm{r}_{\mathrm{e}}$ & 0,13 & $0,42^{*}$ & $0,20^{*}$ & 0,09 & $0,27^{*}$ & $0,24^{*}$ & $0,27^{*}$ & $0,15^{*}$ & - \\
\hline
\end{tabular}

* significativo a $1 \%$ de probabilidade de erro pelo teste $t$. Para dados de $F_{2}(G L=328)$ e $F_{3}(G L=361)$.

Assim como observado por KUREK et al. (2002), BENIN et al. (2003) e BENIN et al. (2005) em aveia branca, o efeito do ambiente (correlações de ambiente) foram na sua maioria negativos. Correlações de ambiente são apontadas como o ambiente favorecendo um caráter em detrimento do outro. Valores positivos de correlação de ambiente indicam que ambos os caracteres foram prejudicados ou beneficiados pelas mesmas variações de ambiente (FALCONER, 1987).

O fato de mesmo os coeficientes de correlações baixos terem sido significativos está associado ao elevado número de graus de liberdade incluídos no teste $t$ (VASCONCELOS et al., 1998). Dessa forma, existe uma tendência dos melhoristas de plantas valorizarem mais o sinal (positivo ou negativo) e a magnitude dos valores na interpretação das correlações. Assim, é de praxe adotar como critério valores de estimativas abaixo de -0,50 e acima de 0,50 (Lopes et al., 2002). Neste trabalho, quando possível, este critério também foi utilizado na discussão dos resultados.

A associação positiva dos caracteres estatura de plantas e rendimento de grãos por planta têm prejudicado a seleção de plantas mais produtivas em trigo, visto que a estatura elevada do trigo facilita o acamamento; por esse motivo, plantas altas são eliminadas no processo de 
seleção (CAmargo 1998; Camargo et al., 1998; CAmargo et al., 2000). Desse modo, as correlações fenotípicas e genotípicas entre EP x RG, nos cruzamentos FUNDACEP $29 \times$ BR 18, BRS $49 \times$ BR 23 e BR 23 x PF 950354, foram todas significativas e positivas (Tabelas 2, 3 e 4). Resultados similares foram obtidos em aveia (HARTwig et al., 2006), e revelam a dificuldade na seleção de plantas produtivas com baixa estatura. Nas gerações segregantes do cruzamento CEP 24 x PF 87504 (Tabela 1), foram observadas magnitudes distintas nas correlações entre os caracteres EP x RG: na geração $F_{2}\left(r_{p}=0,53, r_{g}=0,62\right.$ e $\left.r_{e}=0,33\right)$ e na geração $F 3\left(r_{p}=0,22, r_{g}=0,14\right.$ e $\left.r_{e}=0,33\right)$. Esse comportamento de expressão da correlação genotípica em magnitude considerável na geração F2 e quase ausente na geração F3, está de acordo com as causas de ligação gênica, as quais são causas transitórias de correlação entre caracteres, principalmente em populações derivadas de cruzamentos entre genótipos divergentes (FALCONER, 1987), caso dos genótipos envolvidos neste cruzamento (dados não mostrados).

Nas populações segregantes dos cruzamentos BRS 49 × BR 23 e BR 23 x PF 950354 (Tabelas 3 e 4 respectivamente), os caracteres que se mantiveram correlacionados (fenotípica e genotipicamante) em magnitudes consideráveis com EP, foram os caracteres MEP, MGEP e MMG, e os coeficientes de correlação de ambiente entre os mesmos pares de caracteres desconsiderável.

Caracteres com elevada magnitude de correlação (fenotípica e genotípica) podem ser considerados nas estratégias de seleção (CRUZ e REGAZZI, 1994). Desse modo, uma estratégia que pode ser adotada de acordo com método de condução das populações segregantes deste trabalho, e com base nos resultados obtidos nas populações segregantes dos quatro cruzamentos avaliados, é a seleção indireta por meio do número de afilhos férteis por planta para a obtenção de plantas mais produtivas, visto as correlações obtidas entre os caracteres NAF x RG: cruzamento CEP $24 \times$ PF 87504 (Tabela 1) na geração $F 2\left(r_{p}=\right.$ $0,85, r_{g}=0,98$ e $\left.r_{e}=0,60\right)$ e na geração $F_{3}\left(r_{p}=0,81\right.$, $\mathrm{r}_{\mathrm{g}}=0,97$ e $\left.\mathrm{r}_{\mathrm{e}}=0,60\right)$; cruzamento FUNDACEP $29 \mathrm{x}$ BR 18 (Tabela 2) na geração $F_{2}\left(r_{p}=0,81, r_{g}=0,91\right.$ e $\left.\mathrm{r}_{\mathrm{e}}=0,75\right)$ na geração $\mathrm{F}_{3}\left(\mathrm{r}_{\mathrm{p}}=0,84, \mathrm{r}_{\mathrm{g}}=0,96\right.$ e $\mathrm{r}_{\mathrm{e}}=$ 0,75); cruzamento BRS $49 \times$ BR 23 (Tabela 3) na geração $F_{2}\left(r_{p}=0,73, r_{g}=0,90\right.$ e $\left.r_{e}=0,42\right)$ e na geração $\mathrm{F}_{3}\left(\mathrm{r}_{\mathrm{p}}=0,85, \mathrm{r}_{\mathrm{g}}=0,87\right.$ e $\left.\mathrm{r}_{\mathrm{e}}=0,42\right)$; e no cruzamento BR $23 \times$ PF 950354 (Tabela 4) na geração $F_{2}\left(r_{p}=0,66, r_{g}=0,66\right.$ e $\left.r_{e}=0,80\right)$ e na geração $F_{3}\left(r_{p}=0,92, r_{g}=0,90\right.$ e $\left.r_{e}=0,80\right)$. Todavia, os consideráveis coeficientes de correlação de ambiente observados revelam que os dois caracteres são influenciados pelas mesmas diferenças de condições ambientais. Estes resultados concordam com os obtidos por WaLton (1971), CAMARGO (1998), Camargo et al. (1998), OKuyama et al. (2004) e Silva et al. (2005). A estratégia da seleção indireta pelo caráter número de afilhos férteis por planta é também discutida e indicada por BENIN et al. (2003) e Hartwig et al. (2006) na cultura da aveia branca. De acordo com os resultados, o caráter NAF revela ser boa estratégia de seleção indireta em trigo, uma vez que nesse caráter ocorre associação positiva com o RG e ausência de associação negativa ou positiva com outros caracteres que não fossem de interesse no melhoramento de trigo, exceto nas gerações $\mathrm{F}_{2}$ dos cruzamentos CEP 24 x PF 87504 e FUNDACEP $29 \times$ BR 18 onde houve uma correlação moderada de NAF com EP, podendo então causar um incremento na estatura. Todavia, o caráter NAF é grandemente favorecido nas condições de manejo das plantas (plantas espaçadas) neste trabalho, e resultados bem distintos podem ser obtidos em condição de plantas em competição (plantas em densidade normal de semeadura).

O caráter CEP se correlacionou em diferentes magnitudes de forma positiva, fenotípica e geneticamente com a maioria dos caracteres que compõem a espiga principal nas populações segregantes avaliadas. Tem como os maiores coeficientes de correlação $\left(r_{p}=0,53\right.$ e $r_{g}=0,50$ entre CEP $\times$ NEEP $),\left(r_{p}=0,59\right.$ e $r_{g}=0,69$ entre CEP $\times$ MEP) e $\left(r_{p}=0,52\right.$ e $r_{g}=0,69$ entre CEP $\times$ MGEP) na geração $\mathrm{F}_{3}$ do cruzamento CEP $24 \times$ PF 87504 (Tabela 1), rp $=0,59$ e $r_{g}=0,70$ entre CEP $\times$ NEEP na geração $F_{2}$ do cruzamento FUNDACEP $29 \times$ BR 18 (Tabela 2), e $r_{p}=0,61, r_{g}=0,76$ entre CEP $\times$ MEP na geração $\mathrm{F}_{2}, \mathrm{r}_{\mathrm{p}}=0,73, \mathrm{r}_{\mathrm{g}}=0,84$ entre CEP $\times$ MEP na geração $\mathrm{F}_{3}$ do cruzamento BR 23 x PF 950354 (Tabela 4). Evidencia-se que a associação dos caracteres é fortemente dependente da constituição genética envolvida no cruzamento, como já relatado em aveia por BENIN et al. (2005).

Ainda no cruzamento BR 23 x PF 950354, o caráter CEP revelou elevada correlação genotípica com RG (0,70 na geração $F_{2}$ e 0,89 na $\left.F_{3}\right)$, com reduzido coeficiente de correlação de ambiente em ambas as gerações $(0,10)$, assim como CEP x PMG $\left(r_{g}=0,82\right.$ na geração $F_{2}$ e 0,73 na $\left.F_{3}, \operatorname{com~}_{e}=-0,03\right)$ do mesmo cruzamento. Visando à seleção indireta para rendimento de grãos, esse cruzamento revela ser o mais promissor entre os estudados, uma vez que o caráter CEP é de fácil aferição na seleção em campo. 
Tabela 4. Coeficientes de correlações fenotípicas $\left(r_{p}\right)$, genotípicas $\left(r_{g}\right)$ e de ambiente $\left(r_{e}\right)$ entre os caracteres estatura de plantas (EP), número de afilhos férteis por planta (NAF), comprimento da espiga principal (CEP), número de espiguetas da espiga principal (NEEP), massa da espiga principal (MEP), número de grãos da espiga principal (NGEP), massa de grãos da espiga principal (MGEP), massa de mil grãos (MMG) e rendimento de grãos da planta (RG) das gerações $\mathrm{F}_{2}$ (acima da diagonal) e $\mathrm{F}_{3}$ (abaixo da diagonal) do cruzamento BR 23 x PF 950354. FAEM/UFPel. Pelotas/RS, 2005

\begin{tabular}{|c|c|c|c|c|c|c|c|c|c|c|}
\hline Caráter & & $\mathrm{EP}$ & NAF & CEP & NEEP & MEP & NGEP & MGEP & MMG & RG \\
\hline \multirow[t]{3}{*}{$\mathrm{EP}$} & $r_{p}$ & - & $-0,07$ & $0,36^{*}$ & $0,16^{*}$ & $0,44^{*}$ & $0,16^{*}$ & $0,40^{*}$ & $0,46^{*}$ & $0,24^{*}$ \\
\hline & $r_{g}$ & - & $-0,21^{*}$ & $0,59^{*}$ & $0,21^{*}$ & $0,70^{*}$ & $0,22^{*}$ & $0,87^{*}$ & $0,83^{*}$ & $0,25^{*}$ \\
\hline & $\mathrm{r}_{\mathrm{e}}$ & - & 0,14 & $0,28^{*}$ & $0,18^{*}$ & 0,09 & 0,08 & 0,08 & 0,02 & $0,25^{*}$ \\
\hline \multirow[t]{3}{*}{ NAF } & $r_{p}$ & 0,13 & - & $0,25^{*}$ & $0,28^{*}$ & $0,20^{*}$ & $0,23^{*}$ & $0,16^{*}$ & $-0,02$ & $0,66^{*}$ \\
\hline & $\mathrm{r}_{\mathrm{g}}$ & $0,21^{*}$ & - & $0,66^{*}$ & 0,79 * & $0,77^{*}$ & $0,65^{*}$ & $0,69^{*}$ & 0,00 & $0,66^{*}$ \\
\hline & $\mathrm{r}_{\mathrm{e}}$ & $0,14^{*}$ & - & 0,10 & 0,04 & $-0,13$ & $-0,04$ & $-0,02$ & $-0,02$ & $0,80^{*}$ \\
\hline \multirow[t]{3}{*}{$\overline{\mathrm{CEP}}$} & $r_{p}$ & $0,52^{*}$ & $0,34^{*}$ & - & 0,69 * & $0,61^{*}$ & $0,48^{*}$ & $0,47^{*}$ & $0,17^{*}$ & $0,32^{*}$ \\
\hline & $r_{g}$ & $0,93^{*}$ & $0,31^{*}$ & - & $0,48^{*}$ & $0,76^{*}$ & $0,33^{*}$ & $0,86^{*}$ & $0,82^{*}$ & $0,70^{*}$ \\
\hline & $\mathrm{r}_{\mathrm{e}}$ & $0,28^{*}$ & 0,10 & - & $0,77^{*}$ & $0,56^{*}$ & $0,58^{*}$ & $0,36^{*}$ & $-0,03$ & 0,10 \\
\hline \multirow[t]{3}{*}{ NEEP } & $r_{p}$ & $0,21^{*}$ & $0,19 *$ & $0,60^{*}$ & - & $0,58^{*}$ & $0,59 *$ & $0,47^{*}$ & 0,06 & $0,25^{*}$ \\
\hline & $r_{g}$ & $0,27^{*}$ & $0,60^{*}$ & $0,28^{*}$ & - & $0,89^{*}$ & $0,75^{*}$ & $0,83^{*}$ & $0,95^{*}$ & $0,60^{*}$ \\
\hline & $\mathrm{r}_{\mathrm{e}}$ & $0,18^{*}$ & 0,04 & $0,77^{*}$ & - & $0,42^{*}$ & $0,51^{*}$ & 0,14 & $-0,25^{*}$ & 0,01 \\
\hline \multirow[t]{3}{*}{ MEP } & $r_{p}$ & $0,61^{*}$ & $0,26^{*}$ & $0,73^{*}$ & $0,54^{*}$ & - & $0,78^{*}$ & $0,91^{*}$ & $0,51^{*}$ & $0,41^{*}$ \\
\hline & $r_{g}$ & $0,76^{*}$ & $0,25^{*}$ & $0,84^{*}$ & $0,97^{*}$ & - & $0,92^{*}$ & $0,96^{*}$ & $0,35^{*}$ & $0,82^{*}$ \\
\hline & $\mathrm{r}_{\mathrm{e}}$ & 0,09 & $-0,13$ & $0,56^{*}$ & $0,42^{*}$ & - & 0,68 & $0,84^{*}$ & $0,59^{*}$ & 0,03 \\
\hline \multirow[t]{3}{*}{ NGEP } & $r_{p}$ & $0,34^{*}$ & $0,32^{*}$ & $0,53^{*}$ & $0,48^{*}$ & $0,94^{*}$ & - & $0,81^{*}$ & 0,08 & $0,33^{*}$ \\
\hline & $r_{g}$ & $0,80^{*}$ & $0,37^{*}$ & $0,33^{*}$ & 0,50 * & $0,92^{*}$ & - & $0,83^{*}$ & 0,12 & $0,66^{*}$ \\
\hline & $\mathrm{r}_{\mathrm{e}}$ & 0,08 & $-0,04$ & $0,58^{*}$ & $0,51^{*}$ & $0,68^{*}$ & - & $0,66^{*}$ & 0,06 & $-0,02$ \\
\hline \multirow[t]{3}{*}{ MGEP } & $r_{p}$ & $0,52^{*}$ & $0,23^{*}$ & $0,53^{*}$ & $0,39 *$ & $0,93 *$ & $0,93^{*}$ & - & $0,60^{*}$ & $0,41^{*}$ \\
\hline & $r_{g}$ & $0,33^{*}$ & $-0,18^{*}$ & $-0,06$ & $-0,12$ & $-0,02$ & $-0,35^{*}$ & - & $0,19 *$ & $0,91^{*}$ \\
\hline & $\mathrm{r}_{\mathrm{e}}$ & 0,08 & $-0,02$ & $0,36^{*}$ & $0,14^{*}$ & $0,84^{*}$ & $0,66^{*}$ & - & $0,71^{*}$ & 0,10 \\
\hline \multirow[t]{3}{*}{ MMG } & $r_{p}$ & $0,38^{*}$ & 0,02 & $0,20^{*}$ & 0,05 & $0,63^{*}$ & 0,05 & $0,74^{*}$ & - & $0,25^{*}$ \\
\hline & $r_{g}$ & $0,68^{*}$ & $0,16^{*}$ & $0,73^{*}$ & $0,55^{*}$ & $0,86^{*}$ & 0,03 & $-0,37^{*}$ & - & $0,44^{*}$ \\
\hline & $\mathrm{r}_{\mathrm{e}}$ & 0,02 & $-0,02$ & $-0,03$ & $-0,25^{*}$ & $0,59 *$ & 0,06 & $0,71^{*}$ & - & $0,16^{*}$ \\
\hline \multirow[t]{3}{*}{ RG } & $r_{p}$ & $0,41^{*}$ & $0,92^{*}$ & $0,35^{*}$ & 0,20 * & $0,53^{*}$ & $0,45^{*}$ & $0,52^{*}$ & $0,26^{*}$ & - \\
\hline & $r_{g}$ & $0,58^{*}$ & $0,90^{*}$ & $0,89^{*}$ & $0,49^{*}$ & $0,57^{*}$ & $0,76^{*}$ & $-0,39^{*}$ & $0,43^{*}$ & - \\
\hline & $\mathrm{r}_{\mathrm{e}}$ & $0,25^{*}$ & $0,80^{*}$ & 0,10 & 0,01 & 0,03 & $-0,02$ & 0,10 & $0,16^{*}$ & - \\
\hline
\end{tabular}

* significativo a $1 \%$ de probabilidade de erro pelo teste $t$. Para dados de $F_{2}(G L=263)$ e $F_{3}(G L=364)$.

De modo geral, nos quatro cruzamentos em ambas as gerações houve uma tendência do caráter NEEP se correlacionar positivamente com os caracteres MEP, NGEP e MGEP, bem como a manifestação positiva e de magnitude considerável das correlações de ambiente. Porém, esses valores não interferiram grandemente na manifestação da correlação fenotípica que se manteve em magnitudes consideráveis nessas combinações de pares de caracteres. Nessas associações observa-se que tais caracteres se modificam conjuntamente, ou seja, o aumento no número de espiguetas da espiga propicia incrementos nos outros três caracteres a ele correlacionados (massa da espiga, número de grãos por espiga e massa de grãos da espiga). Esses resultados concordam com os verificados por CAMARGO (1998), para a correlação entre número de espiguetas por espiga $x$ número de grãos por espiga, e por SILVA et al. (2005), para os mesmos pares de caracteres.

Coeficientes de correlação fenotípicas e genotípicas de elevada magnitude, positivos e similares observados entre os caracteres MEP $x$ NGEP, MEP $\times$ MGEP e NGEP $\times$ MGEP em ambas as gerações nos quatro cruzamentos eram previsíveis, uma vez que são caracteres que compõem o massa da espiga, sendo o número de grãos o maior responsável pelo aumento da massa da espiga, e a massa dos grãos da espiga coerente com a massa da espiga pelo fato de a palha da espiga representar 
pequena porção na massa total da espiga. Entre MEP e MMG, todas as gerações, excetuando a geração $\mathrm{F}_{2}$ do cruzamento CEP 24 x PF 87504, expressaram comportamento de associação fenotípicas e genotípicas positivas e em magnitudes consideráveis. Esta correlação é de elevada importância, já que o caráter MEP também revelou correlação com NGEP. Dessa forma, selecionando indiretamente pela massa de espiga obtêm-se ganhos em ambos os componentes da massa de grãos da espiga (NGEP e MMG) das populações avaliadas. O caráter MEP ainda revelou elevada magnitude de correlação genotípica com RG, $\mathrm{r}_{\mathrm{g}}=$ 0,83 na geração $F_{2}$ e $r_{g}=0,92$ na geração $F_{3}$ do cruzamento FUNDACEP 29 x BR 18 (Tabela 2), com reduzida manifestação da correlação de ambiente $(0,18)$. Assim, o caráter massa da espiga principal pode ser considerado na seleção de plantas mais produtivas nesse cruzamento.

Silva et al. (2005) observaram correlações negativas entre massa de grãos por espiga e massa média de grãos estudando gerações fixas de trigos "stay-green". CAMARGo (1998) relatou correlações positivas entre número de grãos por espiga e massa de grãos por espiga, e desta com massa média de cem grãos em populações segregantes de trigo e justificou a importância dessas correlações no melhoramento de trigo. Desse modo, o caráter MGEP revelou boa concordância entre as correlações fenotípicas e genéticas de magnitudes consideráveis com o caráter MMG em todos os cruzamentos, em ambas as gerações. Esse fato corrobora com a seleção indireta sobre o caráter MEP, visto que atua no sentido de incrementar o número de grãos da espiga, conseqüentemente aumenta a massa de grãos da espiga, e ainda está correlacionado com a massa média de grãos, promovendo ganhos para esse caráter também.

Magnitudes distintas de correlação fenotípica e genotípica entre gerações, porém todas positivas nos quatro cruzamentos, foram evidenciados entre MGEP x RG e MMG x RG. Esses resultados colaboram no sentido da busca por plantas produtivas, visto que é possível determinar o rendimento de grãos de uma área por três componentes através do produto: número de espigas x número médio de grãos das espigas x massa média de grãos das espigas (NEDEL, 1994). Dessa forma, em qualquer dos cruzamentos avaliados é possível obter ganhos de alguma forma para o incremento do rendimento de grãos, por meio da seleção indireta nos componentes do rendimento ou em algum deles, sem prejudicar outros caracteres de interesse no melhoramento de trigo.
O estudo da análise de trilha vem complementar e propiciar um exame crítico de fatores específicos que resultam em dada correlação e que possam ser utilizadas com sucesso na formulação de uma estratégia de seleção. Estimativas dos efeitos diretos e indiretos dos coeficientes de trilha sobre o rendimento de grãos estimados a partir das correlações genotípicas das duas populações segregantes dos quatro cruzamentos de trigo avaliados estão inseridas nas tabelas 5 e 6 .

Em estudo mais detalhado sobre as associações obtidas pela análise de trilha, verifica-se que as relações entre o rendimento de grãos, com seus componentes e outros caracteres são pouco diferentes daqueles observados na análise de correlações simples. Assim, o desdobramento das correlações em efeitos direto e indireto justifica as correlações positivas e negativas, de altas e baixas magnitudes entre os caracteres estudados.

Elevada expressão dos efeitos indiretos da correlação genotípica entre EP e RG foram constatados no cruzamento BR 23 x PF 950354 (Tabela 6). Na geração $F_{2}$ desse cruzamento, os caracteres CEP, NGEP e MMG através dos seus efeitos indiretos positivos expressivos $(0,53,0,17$ e 0,15 respectivamente) foram os que promoveram a $r_{g}=0,25$ entre EP e RG, visto o efeito direto negativo de EP sobre RG $(-0,61)$. Na geração $F_{3}$ os caracteres NEEP, NGEP e MMG contribuíram com efeitos indiretos negativos $(-0,13,-0,26$ e $-0,35)$ e os caracteres NAF, CEP, MEP e MGEP que contribuíram com efeito positivo $(0,16,0,31,0,80$ e 0,15 , respectivamente) na $r_{g}=0,58$ de $E P$ com $R G$, porém com efeito direto de EP sobre RG ausente $(-0,06)$. Esses resultados justificam a grande importância do desdobramento das correlações em coeficientes de trilha, uma vez que só assim é possível a visualização mais pormenorizada da verdadeira associação entre os caracteres, bem como o comportamento da expressividade da contribuição direta e/ou indireta dos caracteres na formação da correlação genotípica.

Relação de causa e efeito perfeita foi observada no desdobramento da correlação genotípica entre NAF e RG no cruzamento CEP 24 x PF 87504 na geração F3 (Tabela 5), onde o efeito direto de NAF sobre RG foi correspondente com a correlação genotípica revelada entre eles. Segundo VENCOvsKy e BARRIGA (1992), nessas circunstâncias, a seleção direta sobre o caráter (número de afilhos férteis) será eficiente para melhorar o rendimento de grãos e nenhum outro caráter, entre os avaliados, será afetado por essa estratégia de seleção. 
Tabela 5. Estimativas dos efeitos diretos e indiretos dos coeficientes de trilha, estimados a partir da matriz de correlação genética, sobre o rendimento de grãos em duas populações segregantes $\left(\mathrm{F}_{2}\right.$ e $\left.\mathrm{F}_{3}\right)$ de dois cruzamentos: $\mathrm{CEP} 24 \times \mathrm{PF}$ 87504 e FUNDACEP 29 x BR 18. FAEM/UFPel. Pelotas/RS, 2005

\begin{tabular}{|c|c|c|c|c|c|}
\hline \multirow{3}{*}{ Caráter } & \multirow{3}{*}{ Vias de associação } & \multirow{2}{*}{\multicolumn{2}{|c|}{$\frac{\text { CEP } 24 \times \text { PF } 87504}{\text { Coeficiente de trilha }}$}} & \multirow{2}{*}{\multicolumn{2}{|c|}{$\frac{\text { FUNDACEP } 29 \times \text { BR } 18}{\text { Coeficiente de trilha }}$}} \\
\hline & & & & & \\
\hline & & $\mathrm{F}_{2}$ & $\mathrm{~F}_{3}$ & $\mathrm{~F}_{2}$ & $\mathrm{~F}_{3}$ \\
\hline \multirow[t]{9}{*}{ EP } & Efeito direto sobre RG & 0,23 & 0,08 & 0,11 & 0,21 \\
\hline & Efeito indireto via NAF & 0,37 & 0,10 & 0,19 & 0,03 \\
\hline & Efeito indireto via CEP & 0,00 & 0,00 & $-0,04$ & 0,01 \\
\hline & Efeito indireto via NEEP & $-0,10$ & $-0,03$ & 0,18 & 0,05 \\
\hline & Efeito indireto via MEP & 0,05 & - & 0,15 & - \\
\hline & Efeito indireto via NGEP & 0,00 & $-0,07$ & $-0,08$ & 0,05 \\
\hline & Efeito indireto via MGEP & $-\#$ & - & - & - \\
\hline & Efeito indireto via MMG & 0,03 & 0,06 & 0,02 & 0,05 \\
\hline & Total $\left(\mathrm{r}_{\mathrm{g}}\right)$ & 0,62 & 0,14 & 0,57 & 0,59 \\
\hline \multirow[t]{9}{*}{ NAF } & Efeito direto sobre RG & 0,73 & 0,90 & 0,35 & 0,31 \\
\hline & Efeito indireto via EP & 0,13 & 0,01 & 0,06 & 0,02 \\
\hline & Efeito indireto via CEP & 0,00 & 0,01 & $-0,11$ & 0,00 \\
\hline & Efeito indireto via NEEP & $-0,06$ & 0,01 & 0,41 & 0,10 \\
\hline & Efeito indireto via MEP & 0,06 & - & 0,23 & - \\
\hline & Efeito indireto via NGEP & 0,01 & $-0,03$ & $-0,13$ & 0,05 \\
\hline & Efeito indireto via MGEP & - & - & - & - \\
\hline & Efeito indireto via MMG & 0,01 & $-0,07$ & 0,02 & 0,18 \\
\hline & Total $\left(r_{g}\right)$ & 0,98 & 0,97 & 0,91 & 0,96 \\
\hline \multirow[t]{9}{*}{ CEP } & Efeito direto sobre RG & 0,02 & 0,14 & $-0,20$ & $-0,03$ \\
\hline & Efeito indireto via EP & 0,06 & 0,00 & 0,02 & 0,05 \\
\hline & Efeito indireto via NAF & 0,14 & 0,05 & 0,19 & 0,01 \\
\hline & Efeito indireto via NEEP & $-0,01$ & $-0,21$ & 0,34 & 0,07 \\
\hline & Efeito indireto via MEP & 0,12 & - & 0,21 & - \\
\hline & Efeito indireto via NGEP & 0,03 & 0,19 & $-0,10$ & 0,05 \\
\hline & Efeito indireto via MGEP & - & - & - & - \\
\hline & Efeito indireto via MMG & 0,02 & 0,16 & 0,02 & 0,12 \\
\hline & Total $\left(\mathrm{r}_{\mathrm{g}}\right)$ & 0,38 & 0,35 & 0,44 & 0,36 \\
\hline \multirow[t]{9}{*}{ NEEP } & Efeito direto sobre RG & $-0,27$ & $-0,44$ & 0,49 & 0,20 \\
\hline & Efeito indireto via EP & 0,09 & 0,01 & 0,04 & 0,05 \\
\hline & Efeito indireto via NAF & 0,17 & $-0,03$ & 0,29 & 0,16 \\
\hline & Efeito indireto via CEP & 0,00 & 0,07 & $-0,14$ & 0,01 \\
\hline & Efeito indireto via MEP & 0,14 & - & 0,28 & - \\
\hline & Efeito indireto via NGEP & 0,05 & 0,28 & $-0,19$ & 0,08 \\
\hline & Efeito indireto via MGEP & - & - & - & - \\
\hline & Efeito indireto via MMG & 0,01 & 0,23 & 0,02 & 0,05 \\
\hline & Total $\left(\mathrm{r}_{\mathrm{g}}\right)$ & 0,15 & 0,05 & 0,92 & 0.74 \\
\hline
\end{tabular}


Tabela 5. Conclusão

\begin{tabular}{|c|c|c|c|c|c|}
\hline \multirow{3}{*}{ Caráter } & \multirow{3}{*}{ Vias de associação } & \multirow{2}{*}{\multicolumn{2}{|c|}{$\begin{array}{c}\text { CEP } 24 \times \text { PF } 87504 \\
\text { Coeficiente de trilha }\end{array}$}} & \multirow{2}{*}{\multicolumn{2}{|c|}{$\begin{array}{c}\text { FUNDACEP } 29 \text { x BR } 18 \\
\text { Coeficiente de trilha }\end{array}$}} \\
\hline & & & & & \\
\hline & & $\mathrm{F}_{2}$ & $\mathrm{~F}_{3}$ & $\mathrm{~F}_{2}$ & $\mathrm{~F}_{3}$ \\
\hline \multirow[t]{9}{*}{ MEP } & Efeito direto sobre RG & 0,25 & - & 0,45 & - \\
\hline & Efeito indireto via EP & 0,05 & - & 0,05 & - \\
\hline & Efeito indireto via NAF & 0,20 & - & 0,18 & - \\
\hline & Efeito indireto via CEP & 0,01 & - & $-0,09$ & - \\
\hline & Efeito indireto via NEEP & $-0,16$ & - & 0,31 & - \\
\hline & Efeito indireto via NGEP & 0,08 & - & $-0,25$ & - \\
\hline & Efeito indireto via MGEP & - & - & - & - \\
\hline & Efeito indireto via MMG & 0,01 & - & 0,10 & - \\
\hline & Total $\left(r_{g}\right)$ & 0,47 & - & 0,83 & - \\
\hline \multirow[t]{9}{*}{ NGEP } & Efeito direto sobre RG & 0,09 & 0,42 & $-0,28$ & 0,11 \\
\hline & Efeito indireto via EP & 0,00 & $-0,01$ & 0,03 & 0,09 \\
\hline & Efeito indireto via NAF & 0,08 & $-0,07$ & 0,17 & 0,15 \\
\hline & Efeito indireto via CEP & 0,00 & 0,07 & $-0,07$ & 0,01 \\
\hline & Efeito indireto via NEEP & $-0,14$ & $-0,30$ & 0,33 & 0,15 \\
\hline & Efeito indireto via MEP & 0,22 & - & 0,41 & - \\
\hline & Efeito indireto via MGEP & - & - & - & - \\
\hline & Efeito indireto via MMG & $-0,02$ & $-0,07$ & 0,08 & 0,12 \\
\hline & Total $\left(r_{g}\right)$ & 0,26 & 0,10 & 0,60 & 0,73 \\
\hline \multirow[t]{9}{*}{ MGEP } & Efeito direto sobre RG & - & - & - & - \\
\hline & Efeito indireto via EP & - & - & - & - \\
\hline & Efeito indireto via NAF & - & - & - & - \\
\hline & Efeito indireto via CEP & - & - & - & - \\
\hline & Efeito indireto via NEEP & - & - & - & - \\
\hline & Efeito indireto via MEP & - & - & - & - \\
\hline & Efeito indireto via NGEP & - & - & - & - \\
\hline & Efeito indireto via MMG & - & - & - & - \\
\hline & Total $\left(\mathrm{r}_{\mathrm{g}}\right)$ & - & - & - & - \\
\hline \multirow[t]{9}{*}{ MMG } & Efeito direto sobre RG & 0,07 & 0,43 & 0,13 & 0,36 \\
\hline & Efeito indireto via EP & 0,11 & 0,01 & 0,02 & 0,03 \\
\hline & Efeito indireto via NAF & 0,15 & $-0,15$ & 0,06 & 0,15 \\
\hline & Efeito indireto via CEP & 0,00 & 0,05 & $-0,03$ & 0,01 \\
\hline & Efeito indireto via NEEP & $-0,04$ & 0,11 & 0,09 & 0,03 \\
\hline & Efeito indireto via MEP & 0,03 & - & 0,34 & - \\
\hline & Efeito indireto via NGEP & $-0,02$ & $-0,23$ & $-0,17$ & 0,04 \\
\hline & Efeito indireto via MGEP & - & - & - & - \\
\hline & Total $\left(r_{\mathrm{g}}\right)$ & 0,31 & 0,12 & 0,46 & 0,95 \\
\hline \multicolumn{2}{|c|}{ Coeficiente de determinação } & 0,99 & 1,00 & 1,00 & 1,00 \\
\hline \multicolumn{2}{|c|}{ Valor K usado na análise } & 0,13 & 0,17 & 0,25 & 0,43 \\
\hline \multicolumn{2}{|c|}{ Efeito da variável residual } & 0,08 & 0,00 & 0,00 & 0,00 \\
\hline
\end{tabular}

\# variável problema eliminada após diagnóstico de colinearidade. 
Tabela 6. Estimativas dos efeitos diretos e indiretos dos coeficientes de trilha, estimados a partir da matriz de correlação genética, sobre o rendimento de grãos em duas populações segregantes $\left(\mathrm{F}_{2}\right.$ e $\left.\mathrm{F}_{3}\right)$ dos cruzamentos: $\mathrm{BRS} 49 \times \mathrm{BR} 23$ e BR 23 x PF 950354. FAEM/UFPel. Pelotas/RS, 2005

\begin{tabular}{|c|c|c|c|c|c|}
\hline \multirow{3}{*}{ Caráter } & \multirow{3}{*}{ Vias de associação } & \multirow{2}{*}{\multicolumn{2}{|c|}{$\frac{\text { BRS } 49 \times \text { BR } 23}{\text { Coeficiente de trilha }}$}} & \multirow{2}{*}{\multicolumn{2}{|c|}{$\begin{array}{c}\text { BR } 23 \times \text { PF } 950354 \\
\text { Coeficiente de trilha }\end{array}$}} \\
\hline & & & & & \\
\hline & & $\mathrm{F}_{2}$ & $\mathrm{~F}_{3}$ & $\mathrm{~F}_{2}$ & $\mathrm{~F}_{3}$ \\
\hline \multirow[t]{9}{*}{$\mathrm{EP}$} & Efeito direto sobre RG & 0,38 & 0,56 & $-0,61$ & $-0,06$ \\
\hline & Efeito indireto via NAF & 0,09 & 0,15 & 0,09 & 0,16 \\
\hline & Efeito indireto via CEP & $-0,05$ & $-0,03$ & 0,53 & 0,31 \\
\hline & Efeito indireto via NEEP & $-0,03$ & 0,00 & $-0,02$ & $-0,13$ \\
\hline & Efeito indireto via MEP & $-\#$ & - & - & 0,80 \\
\hline & Efeito indireto via NGEP & $-0,02$ & 0,01 & 0,17 & $-0,26$ \\
\hline & Efeito indireto via MGEP & - & - & - & 0,15 \\
\hline & Efeito indireto via MMG & 0,00 & 0,00 & 0,15 & $-0,35$ \\
\hline & Total $\left(r_{\mathrm{g}}\right)$ & 0,50 & 0,78 & 0,25 & 0,58 \\
\hline \multirow[t]{9}{*}{ NAF } & Efeito direto sobre RG & 1,00 & 0,70 & $-0,44$ & 0,74 \\
\hline & Efeito indireto via EP & 0,03 & 0,12 & 0,13 & $-0,01$ \\
\hline & Efeito indireto via CEP & $-0,13$ & $-0,08$ & 0,60 & 0,10 \\
\hline & Efeito indireto via NEEP & $-0,39$ & 0,00 & $-0,07$ & 0,30 \\
\hline & Efeito indireto via MEP & - & - & - & 0,26 \\
\hline & Efeito indireto via NGEP & $-0,03$ & $-0,01$ & 0,49 & $-0,12$ \\
\hline & Efeito indireto via MGEP & - & - & - & 0,08 \\
\hline & Efeito indireto via MMG & 0,00 & 0,00 & 0,00 & $-0,08$ \\
\hline & Total $\left(\mathrm{r}_{\mathrm{g}}\right)$ & 0,83 & 0,87 & 0,66 & 0,90 \\
\hline \multirow[t]{9}{*}{ CEP } & Efeito direto sobre RG & $-0,24$ & $-0,18$ & 0,90 & 0,33 \\
\hline & Efeito indireto via EP & 0,08 & 0,10 & $-0,36$ & $-0,06$ \\
\hline & Efeito indireto via NAF & 0,58 & 0,30 & $-0,29$ & 0,23 \\
\hline & Efeito indireto via NEEP & $-0,16$ & 0,00 & $-0,04$ & $-0,14$ \\
\hline & Efeito indireto via MEP & - & - & - & 0,88 \\
\hline & Efeito indireto via NGEP & 0,01 & 0,00 & 0,25 & $-0,11$ \\
\hline & Efeito indireto via MGEP & - & - & - & 0,03 \\
\hline & Efeito indireto via MMG & 0,01 & 0,00 & 0,15 & $-0,38$ \\
\hline & Total $\left(r_{g}\right)$ & 0,19 & 0,19 & 0,70 & 0,89 \\
\hline \multirow[t]{9}{*}{ NEEP } & Efeito direto sobre RG & $-0,46$ & $-0,01$ & $-0,09$ & $-0,50$ \\
\hline & Efeito indireto via EP & 0,02 & 0,02 & $-0,13$ & $-0,02$ \\
\hline & Efeito indireto via NAF & 0,92 & 0,44 & $-0,35$ & 0,44 \\
\hline & Efeito indireto via CEP & $-0,07$ & $-0,05$ & 0,43 & 0,09 \\
\hline & Efeito indireto via MEP & - & - & - & 1,00 \\
\hline & Efeito indireto via NGEP & $-0,03$ & $-0,01$ & 0,56 & $-0,17$ \\
\hline & Efeito indireto via MGEP & - & - & - & 0,06 \\
\hline & Efeito indireto via MMG & 0,00 & 0,00 & 0,18 & $-0,28$ \\
\hline & Total $\left(r_{g}\right)$ & 0,23 & 0,39 & 0,60 & 0,49 \\
\hline
\end{tabular}


Tabela 6. Conclusão

\begin{tabular}{|c|c|c|c|c|c|}
\hline \multirow{3}{*}{ Caráter } & \multirow{3}{*}{ Vias de associação } & \multirow{2}{*}{\multicolumn{2}{|c|}{$\frac{\text { BRS } 49 \times \text { BR } 23}{\text { Coeficiente de trilha }}$}} & \multirow{2}{*}{\multicolumn{2}{|c|}{$\frac{\text { BR } 23 \times \text { PF } 950354}{\text { Coeficiente de trilha }}$}} \\
\hline & & & & & \\
\hline & & $\mathrm{F}_{2}$ & $\mathrm{~F}_{3}$ & $\mathrm{~F}_{2}$ & $\mathrm{~F}_{3}$ \\
\hline \multirow[t]{9}{*}{ MEP } & Efeito direto sobre RG & - & - & - & 1,00 \\
\hline & Efeito indireto via EP & - & - & - & $-0,05$ \\
\hline & Efeito indireto via NAF & - & - & - & 0,18 \\
\hline & Efeito indireto via CEP & - & - & - & 0,28 \\
\hline & Efeito indireto via NEEP & - & - & - & $-0,48$ \\
\hline & Efeito indireto via NGEP & - & - & - & $-0,30$ \\
\hline & Efeito indireto via MGEP & - & - & - & 0,00 \\
\hline & Efeito indireto via MMG & - & - & - & $-0,44$ \\
\hline & Total $\left(\mathrm{r}_{\mathrm{g}}\right)$ & - & - & - & 0,57 \\
\hline \multirow[t]{9}{*}{ NGEP } & Efeito direto sobre RG & $-0,05$ & $-0,02$ & 0,75 & $-0,33$ \\
\hline & Efeito indireto via EP & 0,18 & 0,14 & $-0,13$ & $-0,05$ \\
\hline & Efeito indireto via NAF & 0,60 & 0,39 & $-0,28$ & 0,27 \\
\hline & Efeito indireto via CEP & $-0,02$ & 0,00 & 0,30 & 0,11 \\
\hline & Efeito indireto via NEEP & $-0,26$ & 0,00 & $-0,07$ & $-0,25$ \\
\hline & Efeito indireto via MEP & - & - & - & 0,97 \\
\hline & Efeito indireto via MGEP & - & - & - & 0,16 \\
\hline & Efeito indireto via MMG & 0,00 & 0,00 & 0,02 & $-0,02$ \\
\hline & Total $\left(r_{g}\right)$ & 0,43 & 0,51 & 0,66 & 0,76 \\
\hline \multirow[t]{9}{*}{ MGEP } & Efeito direto sobre RG & - & - & - & $-0,46$ \\
\hline & Efeito indireto via EP & - & - & - & 0,02 \\
\hline & Efeito indireto via NAF & - & - & - & $-0,13$ \\
\hline & Efeito indireto via CEP & - & - & - & $-0,02$ \\
\hline & Efeito indireto via NEEP & - & - & - & 0,06 \\
\hline & Efeito indireto via MEP & - & - & - & $-0,02$ \\
\hline & Efeito indireto via NGEP & - & - & - & 0,12 \\
\hline & Efeito indireto via MMG & - & - & - & 0,19 \\
\hline & Total $\left(\mathrm{r}_{\mathrm{g}}\right)$ & - & - & - & $-0,39$ \\
\hline \multirow[t]{9}{*}{ MMG } & Efeito direto sobre RG & 0,01 & 0,00 & 0,19 & $-0,52$ \\
\hline & Efeito indireto via EP & 0,27 & 0,29 & $-0,51$ & $-0,04$ \\
\hline & Efeito indireto via NAF & 0,11 & 0,05 & 0,00 & 0,12 \\
\hline & Efeito indireto via CEP & $-0,06$ & $-0,02$ & 0,74 & 0,24 \\
\hline & Efeito indireto via NEEP & 0,09 & 0,00 & 0,09 & $-0,27$ \\
\hline & Efeito indireto via MEP & - & - & - & 0,90 \\
\hline & Efeito indireto via NGEP & $-0,02$ & 0,00 & 0,09 & $-0,01$ \\
\hline & Efeito indireto via MGEP & - & - & - & 0,17 \\
\hline & Total $\left(r_{g}\right)$ & 0,40 & 0,31 & 0,44 & 0,43 \\
\hline \multicolumn{2}{|c|}{ Coeficiente de determinação } & 0,98 & 1,00 & 0,71 & 0,98 \\
\hline \multicolumn{2}{|c|}{ Valor K usado na análise } & 0,33 & 0,20 & 0,10 & 0,31 \\
\hline \multicolumn{2}{|c|}{ Efeito da variável residual } & 0,13 & 0,00 & 0,54 & 0,12 \\
\hline
\end{tabular}

\# variável problema eliminada após diagnóstico de colinearidade. 
Já pelos resultados dos cruzamentos FUNDACEP 29 × BR 18 (Tabela 5) os caracteres NEEP e MEP na geração F2 e MMG na geração F3, no cruzamento BR 23 x PF 950354 (Tabela 6) os caracteres CEP e NGEP na geração $F_{2}$ e NEEP e MEP na $F_{3}$ revelando efeitos indiretos positivos, e no cruzamento BRS 49 x BR 23 (Tabela 6) os caracteres CEP e NEEP na geração $F_{2}$ revelando efeitos indiretos negativos para a formação da correlação entre NAF e RG, observa-se que esses caracteres causais indiretos devem ser considerados simultaneamente no processo de seleção como sugerido por CARVALHO et al. (2004). Ainda neste cruzamento (BRS 49 x BR 23), foram observados elevados efeitos indiretos de NAF na contribuição da formação da correlação genotípica de RG com CEP, NEEP e NGEP, e o efeito direto negativo desses três sobre RG, o que vem confirmar o elevado efeito direto de NAF sobre RG nas populações desse cruzamento.

$\mathrm{O}$ caráter CEP na geração $\mathrm{F}_{2}$ do cruzamento BR 23 x PF 950354 (Tabela 6) contribuiu com um efeito direto de 0,90 para a correlação genotípica de 0,70 , influenciada principalmente pelos efeitos indiretos negativos de $\operatorname{EP}(-0,36)$ e $\operatorname{NAF}(-0,29)$. Na geração $F_{3}$, o efeito direto foi bastante reduzido em relação à correlação entre CEP e RG, afetada principalmente pelo efeito indireto negativo de MMG $(-0,38)$ e NEEP $(-0,14)$, que por sua vez também revelaram efeito direto negativo sobre RG (-0,52 e -0,50, respectivamente). Ainda para este caráter (CEP), nas duas gerações segregantes dos demais cruzamentos, efeitos indiretos dos caracteres foram tanto positivos quanto negativos, bem como em diferentes magnitudes; nesse caso, os efeitos indiretos é que são as causas das correlações e dificultam estratégias via seleção indireta (VENCOVSKY e BARRIGA, 1992).

As magnitudes consideráveis de correlações entre NEEP e RG não foram correspondentes aos efeitos diretos de NEEP sobre RG nas populações dos cruzamentos FUNDACEP 29 × BR 18 (Tabela 5); os caracteres NAF e MEP foram os que mais contribuíram na geração $F_{2}$ para a correlação entre NEEP e RG; no cruzamento BR 23 x PF 950354 (Tabela 6), na geração $\mathrm{F}_{2}$, os caracteres CEP e NGEP contribuíram grandemente de forma indireta positiva com a correlação de NEEP x RG, e na geração $F_{3}$, os efeitos indiretos mostraram ampla magnitude em ambos os sentidos (negativos e positivos), indicando a dificuldade na seleção, caso a estratégia fosse selecionar via NEEP, visto que deveriam ser considerados todos esses caracteres.

O cruzamento FUNDACEP 29 x BR 18 (Tabela 5) revelou a correlação genotípica de PEP com RG de maior magnitude $(0,83)$, porém efeito direto reduzido
$(0,45)$ na geração $F_{2}$. Dessa forma, chega-se à interpretação de que uma elevada pressão de seleção sobre o caráter MEP pode não garantir ganho satisfatório e neste caso, os efeitos causais indiretos devem ser considerados simultaneamente no processo de seleção. Já na geração $F_{3}$ do cruzamento BR 23 x PF 950354 (Tabela 6), para o caráter MEP, revelando coeficiente de correlação genotípica $(0,57)$ e o efeito direto sobre RG $(1,00)$, pode-se indicar seleção sobre o caráter MEP via seleção indireta para obter incrementos no rendimento de grãos, porém desconsiderando apenas os caracteres EP e NGEP, visto a influência dos demais caracteres na formação da correlação.

A dependência da população na expressão dos coeficientes de correlações e dos efeitos diretos e indiretos na formação dessa correlação foi comentada por LORENCETTI (2004) avaliando dez cruzamentos de aveia branca. No presente estudo, além dessas observações de constituições envolvidas no cruzamento, os dados das diferentes gerações segregantes de um mesmo cruzamento propiciam diferentes resultados (tanto no sentido, quanto na magnitude). Por exemplo, no caso resultados dos efeitos indiretos positivos $(0,17$ e 0,15$)$ na geração $F_{2}$, e os mesmos efeitos $(-0,26$ e $-0,35)$ na $F_{3}$ de NGEP e MMG, respectivamente, na formação da correlação entre EP x RG do cruzamento BR 23 x PF 950354 (Tabela 6), e no mesmo cruzamento, na correlação de NEEP $\times$ RG, com efeitos indiretos de NGEP e MMG $(0,56$ e 0,18$)$ na geração $F_{2}$ e $(-0,17$ e $-0,28)$ na $F$. Desta maneira, fica evidente que a avaliação em uma única geração do cruzamento, bem como, a generalização dos resultados de um ou poucos cruzamentos podem levar à adoção de uma estratégia que poderá não proporcionar ganhos genéticos satisfatórios ou inconsistentes no rendimento de grãos.

Outro exemplo foi o efeito direto positivo do caráter MMG sobre RG $(0,19)$ na geração $F_{2}$ e o mesmo efeito, porém negativo $(-0,52)$ na $\mathrm{F}_{3}$ do cruzamento BR 23 x PF 950354 (Tabela 6), mesmo esse cruzamento revelando correlações genotípicas similares em ambas às gerações, e que foram proporcionadas em grande parte pelos efeitos indiretos dos caracteres EP e CEP $(-0,51$ e 0,74 respectivamente) e CEP, NEEP, MEP e MGEP ( 0,24 , $-0,27,0,90$ e 0,17 respectivamente).

De modo geral, houve uma tendência dos caracteres que compõem a espiga revelarem distintas magnitudes de efeitos diretos, e distintos efeitos indiretos atuando conjuntamente em ambos os sentidos, o que dificulta a indicação de uma estratégia de seleção sem a consideração simultânea dos efeitos indiretos envolvidos. 


\section{CONCLUSÕES}

1. Os resultados distintos observados entre populações de diferentes constituições envolvidas no cruzamento e diferenças entre gerações não permitem a generalização de uma estratégia de seleção nas populações segregantes avaliadas.

2. A seleção de plantas mais produtivas pode ser realizada pela seleção indireta no caráter número de afilhos férteis por planta em qualquer população. Porém, nos cruzamentos FUNDACEP 29 x BR 18, BRS $49 \times$ BR 23 e BR 23 x PF 950354, alguns efeitos indiretos devem ser considerados na seleção.

3. O efeito indireto do caráter número de afilhos férteis é elevado na formação da correlação entre outros caracteres (CEP x RG, NEEP $\times$ RG e NGEP $x R G$ ), sobretudo nas populações do cruzamento BRS 49 x BR 23 e BR 23 x PF 950354.

\section{AGRADECIMENTOS}

Os autores agradecem à CAPES, ao CNPq e à FAPERGS pela concessão de bolsas de Pós-graduação, Iniciação Científica e suporte nesta pesquisa.

\section{REFERÊNCIAS}

ALMEIDA, A.H.B. Heterose e correlações em plantas branquícas e normais de jerimum caboclo (Cucurbita maxima Duchesne). 1988. 95f. Dissertação (Mestrado em Genética e Melhoramento) - Universidade Federal de Viçosa, Viçosa, 1988.

BENIN, G.; CARVALHO, F.I.F.; OLIVEIRA, A.C.; MARCHIORO, V.S.; LORENCETTI, C.; KUREK, A.J.; SILVA, J.A.G.; CARGNIN, A.; SIMIONI, D. Estimativas de correlações e coeficientes de trilha como critérios de seleção para rendimento de grãos em aveia. Revista Brasileira de Agrociência, Pelotas, v.9, n.1, p.9-16, 2003.

BENIN, G.; CARVALHO, F.I.F.; OLIVEIRA, A.C.; HARTWIG, I.; SCHMIDT, D.; VIEIRA, E.A.; VALÉRIO, I.P.; SILVA, J.G. Estimativas de correlações genotípicas e de ambiente em gerações com elevada freqüência de heterozigotos. Ciência Rural, Santa Maria, v.35, n.3, p.523-529, 2005.

CAMARGO, C.E.O. Estimativas de herdabilidades e correlações entre produção de grãos e seus componentes para cruzamentos biparentais de trigo. Scientia Agricola, Piracicaba, v.55, n.1, p.111-118, 1998.

CAMARGO, C.E.O.; FERREIRA FILHO, A.W.P.; FELICIO, J.C. Herdabilidade e correlações entre características agronômicas em populações híbridas de trigo. Bragantia, Campinas, v.57, n.1, 1998.
CAMARGO, C.E.O.; FERREIRA FILHO, A.W.P.; FELICIO, J.C. Estimativas de herdabilidade e correlações quanto à produção de grãos e outras características agronômicas em populações de trigo. Pesquisa Agropecuária Brasileira, Brasília. v.35, n.2, p.369-379, 2000.

CARVALHO, F.I.F; LORENCETTI, C.; BENIN, G. Estimativas e implicações da correlação no melhoramento vegetal. Pelotas: UFPel, 2004. 142p.

CHAUDAURY, D. Genetic variability and correlation for yield components in rice. Indian Journal of Agricultural Sciences, New Delhi, v.43, n.2, p.181-184, 1973.

CRUZ, C.D.; REGAZZI, A.J. Modelos biométricos aplicados ao melhoramento genético. Viçosa: UFV, 1994. 390p.

CRUZ, C.D. Programa GENES - Versão Windows, Aplicativo computacional em genética e estatística. Viçosa: UFV, 2001. 648p.

EMBRAPA. Sistema brasileiro de classificação de solos. Brasília: Embrapa Produção da Informação. 1999. 412 p.

FALCONER, D.S. Introdução à genética quantitativa. Viçosa: UFV, 1987. 279p.

FONSECA, S.; PATTERSON, F.L. Yield components heritabilities and interrelationships in winter wheat (Triticum aestivum L.). Crop Science, Madison, v.8, n.5, p.614-617, 1968.

GONÇALVES, P.S.; MARTINS, A.L.M.; BORTOLLETO, N. Estimates of genetics parameters and correltions of juvenile characteres based on open pallonated of Hevea. Brazillian Journal of Genetics, Ribeirão Preto, v.19, n.1, p.105-111, 1996.

HARTWIG, I.; CARVALHO, F.I.F.; OLIVEIRA, A.C.; SILVA, J.A.G.; LORENCETTI, C.; BENIN, G.; VIEIRA, E.A.; BERTAN, I.; SILVA, G.O.; VALÉRIO, I.P.; SCHMIDT, D.A.M. Correlações fenotípicas entre caracteres agronômicos de interesse em cruzamentos dialélicos de aveia branca. Revista Brasileira de Agrociência, Pelotas, v.12, n.3, p.273-278, 2006.

JOHNSON, V.A.; BIEVER, K.J.;HAUNOLD, A.; SCHMIDT, J.W. Inheritance of plant height, yield of grain, and other plant and seed characteristics in a cross of hard red winter wheat, Triticum aestivum L. Crop Science, Madison, v.6., n.4, p.336-338, 1966.

KUREK, A.J.; CARVALHO, F.I.F.; OLIVEIRA, A.C.; CARGNIN, A.; MARCHIORO, V.S.; LORENCETTI, C. Coeficiente de correlação entre caracteres agronômicos e de qualidade de grãos e sua utilidade na seleção de plantas de aveia. Ciência Rural, Santa Maria, v.32, n.3, p.371-376, 2002.

LOPES, A.C.A.; VELLO, N.A.; PANDINI, F.; ROCHA, M.M.; TSUTSUMI, C.Y. Variabilidade e correlações entre caracteres em cruzamentos de soja. Scientia Agricola, Piracicaba, v.59, n.2, p.341-348, 2002.

LORENCETTI, C. Capacidade combinatória de genitores e suas implicações no desenvolvimento de progênies superiores em aveia (Avena sativa L.). 2004. 102f. Doutorado (Doutorado em Agronomia) - Faculdade de Agronomia Eliseu Maciel, Universidade Federal de Pelotas, Pelotas. 2004. 
MORENO, J.A. Clima do Rio Grande do Sul. Porto Alegre: Secretaria da Agricultura, 1961. 42p.

MORO,G.L.; REIS, M.S.; SEDIYAMA, C.S; SEDIYAMA, T.; OLIVEIRA, A.B. Correlações entre alguns agronômicos em soja (Glicyne max L.). Revista Ceres, Viçosa, v.39, n.223, p.225232, 1992

NEDEL, J.L. Progresso genético no rendimento de grão de cultivares de trigo lançados entre 1940 e 1992. Pesquisa Agropecuária Brasileira, Brasília, v.29, n.10, p. 1565-1570, 1994.

OKUYAMA, L.A.; FEDERIZZI, L.C.; BRABOSA NETO, J.F. Correlation and path analysis of yield and its components and plant traits in wheat. Ciência Rural, Santa Maria, v.34, n.6, p.1701-1708, 2004.

PETR, F.C.; FREY, K.J. Genotypic correlations, dominance and heritability of quantitative characters in oats. Crop Science, Madison, v.6, n.3, p.259-262, 1966.

REUNIÃO DA COMISSÃO SUL BRASILEIRA DE PESQUISA DE TRIGO. Indicações Técnicas da Comissão Sul-Brasileira de Pesquisa de Trigo. Passo Fundo: EMBRAPA-CNPT, 2003, 120p.

SANTOS, J.; VENCOVSKY, R. Correlação fenotípica e genética entre alguns caracteres agronômicos do feijoeiro (Phaseolus vulgaris, L.). Ciência e Prática, São Paulo, v.10, n.3, p.265-272, 1986.
SILVA, S.A.; CARVALHO, F.I.F.; NEDEL, J.L. Análise de trilha para componentes de rendimento de grãos em trigo. Bragantia, Campinas. v.64, n.2, p.191-196, 2005.

STEEL , R.G.D.; TORRIE, J.L. Principles and procedures of statistics. New York: McGraw Hill. 1960. 481p.

TAWARE, S.P.; HALVANKAR, G.B. RAUT, V.M. Variability, correlation and path analysis in soybean hybrids. Soybean Genetics Newsletter, v.24, p. 96-98, 1997.

VASCONCELLOS, N.J.S.; CARVALHO, F.I.F.; COIMBRA, J.M.; SILVA, S.A.; MARCHIORO. V.S.; AZEVEDO, R.; LORENCETTI, C. Efeito do ambiente e correlação entre componentes do grão em genótipos de aveia cultivados no Sul do Brasil. Revista Brasileira de Agrociência, Pelotas, v.4, n.1, p.85-88, 1998.

VENCOVSKY, R.; BARRIGA, P. Genética biométrica no fitomelhoramento. Ribeirão Preto: Revista Brasileira de Genética, 1992. 496p.

WALTON, P.D. The use of a factor analysis in determining characters for yield selection in wheat. Euphytica, Dordrecht, v.20, n.3, p.416-421, 1971.

WRIGHT, S. Correlation and causation. Journal Agriculture Research, Islamabad, v.20, p.577-585, 1921. 